\title{
Utilising the Internet to Improve Peasant Artisan Incomes: Evidence from Mexico
}

\author{
John Dobson $^{1}$, Richard Duncombe ${ }^{2}$, and Brian Nicholson ${ }^{1}$ \\ ${ }^{1}$ Manchester Business School, The University of Manchester, Booth Street West, \\ Manchester, Gtr Manchester M15 6PB, UK \\ ${ }^{2}$ School of Environment and Development, The University of Manchester, PO Box 88, \\ Manchester, M60 1QD, UK \\ john@southoftheborder.ca, richard.duncombe@manchester.ac.uk, \\ brian.nicholson@manchester.ac.uk
}

\begin{abstract}
This paper examines whether the Internet can be used to improve peasant artisan incomes by connecting producers directly with global markets. The paper surveys previous research which suggests that Business to Business artisan portals within most Developing Economies have failed to deliver expected benefits. This paper identifies some of the significant obstacles to successful implementation and presents an institutional framework that provides for rational incentives. Drawing upon new institutional economics, we propose that the Internet can be the catalyst for positive change in artisan incomes. To illustrate the argument, we examine institutions within the Mexican handicraft market and highlight current challenges. The proposal presented involves readily available technology for both artisan and small retail stores to exploit their comparative advantage, leading to a sustainable model for artisan economic development.
\end{abstract}

Keywords: New Institutional Economics, Livelihoods and Markets, Innovation, Handicrafts, Development, ICT, Internet, Developing Economies.

\section{Introduction}

Travellers to developing economies (DEs) often encounter locals selling handicrafts. Products can be locally made or brought in from various regions of the country to satisfy tourist demand for 'authentic' goods. Purchasing such items is considered integral to both the visitor's tourist experience and an important part of livelihood strategies for peasant communities. Based on these premises, handicraft production has historically been identified as an invisible export and part of a survival pattern for peasant communities [1]. This area of trade and development is important and a number of organisations such as UNESCO through their 'Seal of Excellence' and the Fair Trade Movement are attempting to improve artisan incomes that derive from the expansion of global markets for handicrafts. The sustainability of these ventures is based on the ability to gain and maintain market share. However, sustainability of 
development initiatives is difficult to maintain with low quality production. The issue of poor quality (e.g. cracks, poor fit and finish) must be overcome to complete the transactions and ensure repeat business. However, defects can also be passed off as normal characteristics of handmade items that perhaps add authenticity to the product. The sale may have an implicit acknowledgement of unsatisfactory quality by one or both parties if during negotiation the vendor mentions or the buyer considers the charitable benefit associated with completing the exchange.

Based on an analysis of evidence from the Mexican handicraft industry, this paper will discuss the causes of low quality production and the resulting low artisan incomes.Research indentifies potential benefits of Information Communication Technology (ICT) for increasing DE participation in international trade [2, 3]. This paper builds upon Boateng's research plus that of Pare [4] to examine the causes of high failure rates of Information Communication Technology for Development (ICT4D) initiatives. While there tends to be general agreement on the potential benefits of ICT4D, the results have been disappointing. Some researchers identify structural problems such as limited access, high cost and lack of human capital to successfully implement ICT4D [5]. Other research [2] examined institutional barriers that contributed to the high failure rates. Successful Business to Business (B2B) projects require contextualising technology applications to local conditions.

While there is a concern that globalisation has undermined peasant livelihood options, Medina and Santos [1] highlight the opportunity for economic development through the exploitation of indigenous handicrafts. The Ricardian model of comparative advantage calculates that world trade should be $500 \%$ higher [6]. Where is the missing trade? Pare [4] proposes that Transaction Costs of these types of B2B portals are still too high for these initiatives to be successful. Institutional theory builds upon the transaction cost paradigm to help explain why markets fail to realise opportunities. Our research focuses on how peasant artisans can utilise the Internet to further sustain economic development.

There may be applications for development practitioners attempting to establish sustainable livelihood initiatives in other DEs. We highlight opportunities for handicraft producers from DEs to use ICT to exploit their comparative advantage (i.e. low production costs, product customisation) while moving up the value chain. ICT may be viewed as a tool that can bypass the current obstacles (blocking agents) to successful development and it can be coupled with the application of new institutional economic (NIE) theory to e-commerce projects. NIE theory can assist in developing sustainable solutions by contributing knowledge on: establishing rational incentives to produce higher quality products, increasing accountability, providing information feedback and establishing innovation rents. ICT may foster institutions that will encourage innovation and permit sustainable peasant artisan development. Once the technical implementation and infrastructure is built, peasant entrepreneurs should be able to work at the margins [7] to dramatically improve incomes.

We attempt to provide an initial theoretical approach for practitioners and researchers. By combining NIE theory with market based approaches (or business theory) the paper attempts to build a new framework for researching ICT4D initiatives. An NIE perspective of participant behaviour could yield opportunities to change incentives within specific industries to make livelihood projects more sustainable. The development practitioner may discern more complex explanations for 
project underperformance and identify new approaches that will increase the likelihood of future implementation success.

The paper is divided into three sections. The first section will examine both NIE and ICT4D literature. We examine North's seminal work on the role of institutions in successful development and review current ICT literature from an institutional paradigm, to understand the general causes of development failure. Section two examines the specifics of the Mexican handicraft market. Game theory is used to highlight behaviour that tends to deviate from modern business practices and often results are both low quality production and sub-optimal welfare outcomes for peasants. Artisan survival behaviour must be understood prior to successful implementation of future development initiatives. The third section attempts to provide a way forward for both researcher and practitioner. ICT is a tool that has dramatically lowered transaction costs, yet development has failed to materialise. ICT can be an effective tool in creating sustainable community development by altering the incentives within the handicraft industry to rationally connect artisans with global markets. The relationship requires careful management for both the buyer and the artisan. A development manager (DM) helps lower the transaction cost while mitigating risk for the buyer and seller. The role of the DM is critical and manages both buyer and seller expectations of the transactions given these parties come from vastly different societies. While understanding the need to contextualise technology to local conditions, this ICT4D proposal identifies institutional transformation within the handicraft industry, as a key to sustainable development. Providing artisans with rational incentives to improve quality should dramatically increase incomes. The paper provides a theoretically sound approach to B2B relationships in DE. Future research will be directed at piloting the proposed implementation concepts.

\section{Literature Review and Relevant Concepts}

The ability to maintain market access may be ultimately determined by the ability of producers to respond effectively to market requirements. The first suggestion to improve artisan production builds upon the concept of Lean Production successfully used by Toyota. Toyota, after WWII rebuilt production with depleted resources by creating 'just in time' production. Peasant artisans with limited capital can benefit from a similar production approach by first finding the buyer and producing to meet demand. The second aspect is then to ensure a quick response to market demands. Zara Clothing Company (Zara) created a competitive advantage by using this strategy [8]. The lessons from these two approaches can be applied within the handicraft market to establish a supply chain. The process involves converting previously considered weaknesses, of limited capacity and primitive technology, to create a competitive advantage of shorter production cycles, customisation and 'just in time' delivery. Historically the dramatic drop in transportation and communication costs facilitated specialisation and promoted international trade. The Internet is a tool that may provide opportunities for small scale producers to market directly to small retail consumers, thereby aligning production capacity with consumption or market needs.

Research done [2] tends to group ICT4D literature into three main themes. The first area of research focuses on the potential benefits and constraints of e-commerce to 
further development. This includes the need to contextualise ICT initiatives to local realities. While acknowledging the role of institutions in creating challenges, it tends not to address the institutional constraints. This research tends to simply be content to indentify the problem. This presents institutions as unexamined black boxes that can be signalled as part of the causes for development failure. The second main theme deals with the technical barriers of B2B initiatives. This research tends to focus on limited access in DE, proportionally higher costs in DE versus Developed Countries, or the lack of human capital to successfully implement ICT4D. This approach could be identified as the 'field of dreams' explanation: "If we build it, development will happen". Mann [9] argues that once the technical obstacles are overcome developing economies will leapfrog. The third theme deals with support and implementation of initiatives. The topics tend to discuss issues of support by government and practitioners [2].

There is a widening gap in economic performance between many DE and Developed Economies that is caused by insufficient input spending on IT (software and equipment) rather than productivity shortfall [10]. Some of the technical issues include accessibility; research finds that in Mexico, Internet access consumes $5 \%$ of disposable income. The two most important barriers to successful e-commerce tend to be cost and limited resources [5]. Further hindering decisions to invest, in B2B initiatives, is inability of disadvantaged firms to absorb financial losses [11]. The research done by Pare [4] indentifies other technical problems such as; issues of quality, payment settlement, logistics and customs as still impeding development.While acknowledging that technical deficiencies must be addressed prior to successful introduction of modern factories and realisation of economies of scale, most ICT4D research was not concerned with macro economics, but examined industries, communities or individual firms. The technical explanation fails to explain why available technologies are not adopted and people do not utilise existing knowledge to maximise profits or product quality [12].

Heeks and Wilson [13] argue that a technical explanation tends to present a very narrow view of the development challenges and fails to recognise the complex interplay of social, cultural and economic arenas within any industry. Technology should be appropriate within a socio-cultural environment and attempt to build trust [2]. Boateng further argues that there is a knowledge gap between understanding the potential benefits and the ability to contextualise the problem within societal institutions. The research shows that there is an unrealised potential. There is a major incentive for (artisan) firms to adopt ICT and gain market access [2]. However, the Internet is primarily used for email and most had never used the Internet for market research [2]. Unfortunately, research done by Pare [2] found that the benefits may be overstated. More discouraging were Batchelor and Webb [14] who were unable to find a single Internet based B2B transaction and many of the ventures studied have closed. Stating the Internet has limited prospects for selling handicraft, they recommend that initiatives should focus on "ethical (fair trade) tourism" [13]. The diffusion of technology is making the process easier, but it does not make it automatic [15].

The drop in communication costs have failed to create new markets even though buying direct presents the potential of substantial price savings. Flexible manufacturing and mass-customization have been topics of managerial research for some time. Given the extensive ability of e-Commerce applications to capture user preferences and behaviour, it is odd that researchers have not fully explored the challenges and 
consequences of integrating these systems with mass-customization design and manufacturing systems [3]. Development practitioners proposed that DE handicraft development could similarly benefit from vigorous adoption of ICT. Rabinovich et al [16] find that Internet based purchases are able to deliver efficiencies by allowing buying decisions to be postponed. The efficiencies benefit both the supplier and consumer [17]. Yet most retailers have avoided buying directly and continue to use traditional distribution methods such as sales reps and trade shows. A reason cited by Pare [2] is that the introduction of the Internet has not reduced the transactions costs to an extent where a significant impact on Artisan B2B sales takes place. The portals have not lowered the coordination costs or lowered information asymmetry sufficiently to encourage the adoption of this new supply chain. While tending to agree with the conclusion reached by Pare, there is still an element missing from the discussion. It is counter intuitive that the substantial price difference between the LDC market price and the DC market price has not encouraged entrepreneurial investment. The lack of sustainable ventures tends to indicate that the vast majority of investments fail. Examining institutional deficiencies is required to help explain these setbacks.

Repeat business is critical to provide the incentive to improve quality. Online feedback mechanisms have emerged as a viable mechanism for fostering cooperation among strangers in such settings by ensuring that the behaviour of a trader toward any other trader becomes known [18]. The trust mechanism in e-commerce must be built [19]. The international customer would have the ability to order products as required with minimum investment. Rabinovich et al [16] find that Internet based purchases are able to deliver efficiencies by allowing buying decisions to be postponed. Retail buyers are able to customise products in small batches. This presents the small scale artisan with a potential advantage.

NIE incorporates a much more complex explanation of deficient institutions and perverse incentives than can be covered in this paper $^{1}$. The focus here is on some aspects of NIE that deal specifically with market mechanisms. The implications are that by altering institutions to provide rational incentives, economic development would develop organically. The process involves altering market demand for handicrafts. The current paradigm involves maximising profits, price competition, high discount rate, low loyalty, poor quality and ultimately low artisan income.

NIE theory $[12,20]$ provides an explanation for why states fail to develop robust institutions and the resulting development failure. The infrequency of "late late" developers indicates the difficulty in successfully overcoming socialised behaviour. There is extensive research on ICT readiness. A common theme focuses on the technical obstacle (costs of infrastructure and access) to sustainable B2B projects. B2B initiatives focus on business to business portals. Researchers further examine the need to appropriately introduce ICT within local contexts [2]. While agreeing that any ICT4D initiative must be contextualised within the normative rules of society, we argue that ICT can potentially by-pass the barriers to development and create new institutions.

Entrepreneurs must consider many factors in determining investment decisions. The overriding consideration is the likelihood that the investment will generate a

\footnotetext{
${ }^{1}$ For a more detailed explanation see [38] and [39].
} 
profit to warrant the risk incurred. While opportunities will vary between industries and countries, Neo-classical economics indicate that profitability should be greater in a DE, since the ratio of labour to capital is lower [21]. This does not reflect the historical pattern of investment. NIE emerged as an effort to explain failure of DEs to develop, by building on the neo-classical model of scarcity and adding a role for institutions [20]. Game theory concept of cheating ${ }^{2}$ may be considered part of an unresolved distributional conflict. In the Mexican handicraft industry it results from low sanction and accountability mechanisms. In pre-modern societies relationships were clan or family centred, resulting in low transaction costs and high accountability, therefore ideology and culture can help explain the persistence of 'inefficient' markets [20]. When opportunities for innovation or trade occurred, existing institutions must undergo adaptation. It is institutions that reduce uncertainty and permit non-personal exchange, allowing for specialisation and realisation of economies of scale [21, 22]. However, in most societies misaligned incentives result in suboptimal economic performance. The inability to resolve the conflict between institutional constraints and economic opportunity makes the process of economic development prone to breakdown.

Individuals invest based on the certainty that deferring consumption in favour of accumulation will result in a high payoff [21]. Insecure property rights discourage economic growth. The process of improving quality requires healthy competition that permits innovation rents. Historically, organisations like champagne fairs and trade guilds enforced scarcity and guaranteed quality [23]. What makes champagne valuable is the precise balance of scarcity and reputation for quality that has developed based on competition from various producers within the region and external competition with other producers of sparkling wine. The medieval world was able to have non-personal exchanges dispersed across continents. It did not seem to matter if products or money were sent first [24]. Societies had been able to institutionalise community responsibility.

It is generally understood in development literature that perverse incentives that reward cheating lead to underdevelopment. This results in low quality production for much of the Mexican handicraft industry. When examining the handicraft industry we find millions of artisans struggling to acquire the very basics for human existence [25] in an industry dominated by the most marginalised members of peasant communities [26]. The marketing is mostly carried out by women and children at various markets and town squares throughout the country. This process leads to path dependence which places a sub-sector of society on the road to continuous underperformance. The condition, while not permanent is difficult to change once behaviour has become socialised [20]. In comparing successful developers from unsuccessful "there is little doubt that the 'good' institutions established in the settler colonies formed the foundation of current prosperity" [27]. The institutional framework that marginalises these populations facilitates the emergence of blocking agents which conspire to thwart economic progress by undervaluing handicraft production.

\footnotetext{
${ }^{2}$ The literature reviewed on game theory use the terms 'cheat', 'appropriate' and 'defect' interchangeably.
} 


\section{The Handicraft Market - Today}

Throughout the world artisans live on the fringes of societies, a marginal and precarious existence [28]. Artisan production is influenced by market forces and non market forces such are societal obligations [26]. Production is usually carried out by landless peasants, who hope to earn enough to gain access to land to become subsistent farmers. Handicrafts are a viable income option for peasants, since products are usually made from readily available local materials. Products are extremely profitable on a per unit basis. The input material costs tend to be about $30 \%$ of wholesale pricing leaving a $70 \%$ residual $^{3}$. Artisan handicraft production is mostly done at home with most members of the immediate family playing an active role. Artisan families tend to divide labour with men producing and working mechanised equipment while the women and children focus on marketing the products at local or regional markets and tourist locales. Women may also assemble beaded jewellery or other manual task while at markets. Handicraft production tends to be done during leisure time and around survival activities (like planting, harvesting or tending flocks) and societal obligations (like religious festivals, family commitments and community events). At times of strong market demand, production tends to be postponed ensuring survival activities are completed. If additional staff is considered, the first choice is an immediate family member or close friend. It is rare to find non-family members working within an artisan family business since there is a much higher risk of piracy. In these types of home based firms innovative artisans are unable to realise economies of scale by specialising the production process.

The artisan market consists of a matrix of both wholesale and retail/tourist customers comprising both domestic and international buyers. Each buyer type will be discussed. The domestic/tourist buyer tends to purchased out of a moral sense of charity. In Mexico the buyer inserts a perverse incentive for the producer since the buyer's decision is based on moral and not economic / welfare optimisation grounds. The handicraft market relies on charity in a society that tends not to be charitable [26].

The Domestic wholesale customer tends to buy at local markets to re-sell the product at tourist resorts. There is little respect for design property rights. The focus is on the lowest price to maximise profits. There is a high discount rate, since tourists at these resorts tend not to return with defective products. Mexican silver has a negative brand caused by the cumulative effect of millions of tourist buying low quality products. The international wholesale buyer often behaves similarly to the domestic wholesale buyer in the search for the best price. When and if the international buyer attempts to introduce rational incentives or western business practices there is institutional resistance. The infrequency of buying trips (only a few times per year) results in the producer having a high discount rate. "Handicrap" is a term often used by international buyers to describe the quality of products. Products often require high discounts to retail pricing once defects are discovered. Artisans rationally adjust time and effort in production in response to anticipated returns. It is in the artisan's best interest to maximise short term profits. The ability to credibly commit to repeat business is undermined by the high transactions costs associated with international travel both in terms of time and expense. ICT/Internet is able to eliminate the travel costs.

\footnotetext{
${ }^{3}$ Detailed research done on various handicraft cluster in Mexico for my MSc dissertation.
} 
The low cost of accessing these products, via the Internet, has the potential of increasing transaction frequency. The added benefit of virtual travel is to substantially reduce carbon footprint which improves the sustainability of both the business model and the environment.

Game theory can help illustrate several aspects of decision making which may lead to sub-optimal welfare outcomes [29]. We will apply game theory concepts to the Mexican handicraft industry. A variation, called Agency Game, was developed to examine business cooperation. In this game the principal acts first in deciding whether to invest in a business venture or technological innovation. Then the agent has the option of cooperating or appropriating. If the agent cooperates, both parties gain and divide the residual [30]. However, the agent has an incentive to appropriate the investment since this would earn a larger wage. If there is no consensus over behaviour and deviation is not penalised, then opportunism will dominate. Culture matters, in that once punishment becomes socialised it becomes a re-enforcing mechanism which is easily maintained. High enforcement results in almost total efficiency [30]. Low enforcement results in increased appropriators and sub-optimal outcomes for society. This explains a significant aspect of artisan production behaviour and resulting low incomes. Altering the rules of the game has the potential of dramatically improving artisan incomes. Part of the solution to ensuring cooperation is to lower the discount rate on future business. The Internet is able to encourage repeat play by easing future buying.

Agency game presents a peculiar twist in the Mexican handicraft industry. Research indicates that in rural Haciendas of the $18^{\text {th }}$ Century, it was the peasant that deliberately assumed large debt to guarantee employment [31]. The societal institutions that created artificial land scarcity and labour surplus provided perverse incentives for individuals to become indentured. Game Theory indicates that appropriation should preclude repeat play. In the Mexican handicraft market workers still respond to the scarcity of few buyers by appropriating cash deposits to ensure future income.

The Principal provides the Agent with cash from advance from which they are to buy materials for their piecemeal work. The Agent must have a low discount rate, since appropriation will earn the highest income if there is no repeat play. Appropriation usually occurs within the first two years, as the Agent is 'forced' to take the cash advance; the usual cause is a social commitment, or unforeseen medical emergency. There is very little legal recourse available. First, the amount of the loan is relatively insignificant to the principal. Second the peasant can simply hide until the buyer leaves town. Third the time and costs involved pursuing legal recourse often exceeds the loss. Consequently appropriation, rather than disqualifying the Agent, in fact serves to guarantee employment as long the Principal remains in the industry. The agent will promise to re-pay the 'loan' in the form of future production. Many foreign buyers are unwilling to accept this type of theft will write off the loss and discontinue buying. The regularity of this occurrence ${ }^{4}$, leads to the conjecture that Mexican workers continue to utilize this modern version of indentured service which can be described as Mexican Agency Game. The Principal is forced to limit investments to

\footnotetext{
${ }^{4}$ While appropriation can be considered part of unresolved distributional dispute; the regularity of appropriation in all parts of Mexico indicates that this is still used as an employment guaranteeing strategy.
} 
willingly forfeitable amounts. Orders are small and dispersed amongst various producers of similar items.

The buyer may at times request various artisans to make the same item to mitigate the risk of appropriation. The artisan has low incentive to innovate for a market that readily pirates designs. The result is low innovation and constant competition on price. Any attempt by Artisans to earn an innovation rent from design or quality is quickly undermined by the buyers the willingness to accept duplication from other producers. The process in Mexico is called 'Malbaratada', literally translated 'cheap and poorly made'. The market is continuously being supplied with cheaper less well made products which offer the potential for higher profits [32]. The low sanction for piracy and the difficulty in determining quality provides strong incentives to reduce the inputs and maximise profits. Beyond normative adherence to honesty there are few mechanisms to guarantee quality.

A relevant example occurred during a buying trip of one of the authors. After selecting a variety of items for a specific artisan and inquiry was made about a silver chain. The vendor seemed to have an unusually large quantity but the Artisan was quiet and hesitated in quoting a price. After some persistence he disclosed that the item was counterfeit Sterling. The chains had been made specifically for unsuspecting tourists but offered reassurance that the rest of the production was actually sterling. The Agent resisted cheating behaviour because he had a low discount rate for future business. However, a tourist that cannot commit to repeat business is subject to a high discount rate. The tourist would marvel at the great bargain, at least until their neck turned green.

The process of introducing rational incentives begins with understanding that producers have no incentive to improve quality because of the high discount rate and extensive piracy. An industry with low sanctions will reward cheating behaviour. This can be most easily accomplished by lowering the quality of inputs (materials, time, and effort). What has emerged is the 'Malbaratada' or market for lemons. However, Game Theory demonstrates that repeat play is sufficient credible commitment to increase welfare outcome. The goal is to successfully combine relevant aspects of NIE theory, such as property rights, innovation rents, lowering transactions and increasing nonpersonal exchange, to existing Internet technology. This approach has the potential of creating an institutional framework that can provide rational incentives to improve quality.

\section{Moving Forward: Connecting Artisans to Global Markets}

Altering the incentives may not be possible until blocking agents are removed. Mexican society inserts perverse incentives that undermine development of a rational industry. Within the silver industry, the national government involvement in promoting the silver industry may in fact undermine quality and encourage the production of unmarketable products. The Feria Nacional de Plata's mandate is to promote the Taxco Silver industry. The mandate states that Taxco's silver production is part of Mexico's pre-Hispanic heritage. Artisans from any region of Mexico are welcomed to submit products. Part of the mandate is to promote culture [33]. The National Silver 
Fair has created the myth of Taxco as an ancient silversmith centre. Evidence shows that the industry actually began in 1931 when William Spratling started the first silver shop [34]. The mandate undermines the establishment of an innovation cluster by not limiting production to a geographic area, like Champagne. The winner of the design competitions is presented with a trophy of an Aztec warrior from the President of the Republic [34]. The artisan becomes a defender of Mexico's pre-Hispanic culture. The production of pre-conquest cultural representations has encouraged the production of non marketable items. Many of the best workshops in Taxco proudly display winning production. These items are readily offered for sale with very few buyers. The government's attempt to promote the silver industry misaligns the incentive structure and has encouraged artisans to misappropriate investments of time, effort and resources. NIE explains how behaviour once institutionalised is difficult to change.

The handicraft market could build new institutions to rationally align the principal/agent relationship or producer/buyer. Protecting artisan property rights, limiting piracy and credibly committing to repeat business should encourage innovation (and corresponding rents) and sustainable repeat business. The process is cost effective using existing Internet technology.

The project involves prototyping and establishing an Internet portal to connect producers to small retailers in international markets. Both these groups have failed to realise some of the potential benefits of globalisation because of their respective small size. Most small retail stores, in developed countries, have been unable to buy directly from overseas suppliers. The challenge is that manufacturing companies require minimum 40 foot container loads of any specific item. This is unrealistic method of purchasing for retail stores since the volume and cash flow requirements preclude this type of investment. The second difficultly is any attempt to buy directly from handicraft producers faces a high transaction cost. Therefore, most small retail stores continue to rely on traditional distribution systems. The inability to access DE suppliers results in sub-optimal performance when faced with competition from large multinational who realise these economies of scale. The current supply chain effectively excludes artisans from participation. Small producers are unable to meet the requirements of both quality and quantity manufacturing of large multi-nationals corporations. What is required is a unique supply chain that focuses on the strengths of both artisan producer and small retail consumer.

The proposed initiative requires the creation of an intermediary, or Development Manager (DM) to act as an agent of change, instituting NIE theory on the industry. This is accomplished utilising ICT to help create new institutions. The DM would be based in the artisan community with the job of coordinating the purchase from various artisans for international buyers. DMs are capable of changing the paradigm by using small scale production of various artisans as an asset instead of a liability. The Internet can connect producers, which can only produce small quantities with consumers that only require small amounts and require a lot of variety. A retail store is able to purchase as little as a small box to be profitable.

Retail stores do not currently capitalise on these potential profits because of the risks associated with international commerce. As well, because they only require small quantities the transaction costs of directly travelling to many regions of the world is prohibitive. An Internet portal could allow retail stores to buy small quantities directly 
without travelling. The financial transactions would be handled through an intermediary company based in the developed world. This would lower the risks for buyers, since western businesses have historically adhered to reputation and honest business practices to lower the transaction costs [35]. This would serve to mitigate the risks associated with direct buying. This portal could connect thousands retail stores with hundreds of artisans employing thousands of artisans. The Internet is a tool to help build a solution. What is required is the establishment of incentives for quality and innovation. The role of the DM is to train and educate artisans to market demands and protect artisan design rights by allowing them to profit from innovation rents. The DM must therefore be an honest broker, ensuring the rights of the buyer and seller are protected. Prior research identifies how $3^{\text {rd }}$ parties are able to increase trust in a system by minimising the potential of fraud [24].

The role of the DM is critical in ensuring property right protection. Assistance may be provided involving cosmetic changes in colour or patterns based on current trends or more substantive product modification. The goal is to take what is being produced and modify it to what customers actually want and when they want it. The process involves working within existing technical capacity to create the best possible product. Overcoming the discount rate is the difficult part, since the producers function in a market that seeks 'Malbaratada'. Establishing innovation rents should encourage investment in better products and increase the likelihood of repeat business. To establish rational incentives to innovate, the artisan maintains an innovation rents to their design within the Internet portal. As orders increase, the artisan will face increase demands on their leisure time. The profit potential should encourage some to invest in productivity enhancing technology or hiring of specialised labour. The risk of hiring non-family labour has already been discussed. Once an employee has been hired it would be difficult to prevent the designs from being appropriated and diffusing into the local market. This loss would be mitigated, for the artisan, if there are consistent Internet orders to offset losses in the local market. The piracy into the local market will be difficult to stop. It does have a positive spill-over effect of helping educate the other artisans of current trends in the market. This may help strengthen the existing local market and increase general demand.

The high margins and the ability to differentiate competitors will encourage repeat purchases of items that sell well. The process of repeat purchases will provide the appropriate information feedback for producers to learn market requirements. The process allows the customer to have product arrive just in time. The benefits of direct buying are significant for the retail store. Comparing traditional buying options against the Internet Portal Direct Purchase option shows that a B2B option is profitable. $\$ 5,000$ in retail sales would yield a $50 \%$ increase in profits. The biggest savings comes from the Cost of Goods Sold. In this example the buyer replaces domestically sourced products (whether imported or not) with handicrafts at market prices from a DE. There are additional expenses associated with importing directly such are duties, brokerage fees and a commission to the DM. When comparing the bottom line buying direct is much more profitable. See Table 1 for detailed numbers.

In the previous section we discussed how the high travel cost would make frequent trips impossible. The ability to buy from Mexico without travelling is technologically 
possible and potentially profitable. While a $\$ 1,000$ wholesale purchase to a retail store is a small investment. The same $\$ 1,000$ purchase in Chiapas or any other desperately poor region is a significant amount. This process would target income to the most marginalised sectors. A few orders would have the ability to double artisan income. The inability to provide enough variety presents a challenge, however the Internet portal can overcome this problem5. The portal would permit easier re-ordering. This would provide appropriate feedback and significant positive reinforcement. Consistent re-orders should encourage additional effort and reward innovation. This approach would improve quality and create a virtuous cycle of innovation.

Table 1. Comparison of Traditional and Internet Portal Direct Purchase (IPDP)

\begin{tabular}{lcccc}
\hline & $\begin{array}{l}\text { Traditional } \\
\text { Purchase }\end{array}$ & & IPDP \\
& & & $\$ 5,000$ & \\
\hline Retail Sales & $\$ 5,000$ & $50 \%$ & $1,000^{* *}$ & $20 \%$ \\
Cost of Goods Sold & $2,500[37]$ & $5 \%$ & 150 & $3 \%$ \\
DM Commission & - & & $300^{\wedge}$ & $6 \%$ \\
Freight In & $250^{* * *}$ & & $100^{\wedge \wedge}$ & $2 \%$ \\
Duty \& Taxes & - & $55 \%$ & $75^{\wedge \wedge}$ & $2 \%$ \\
Brokerage & - & $45 \%$ & 1,645 & $33 \%$ \\
Expenses & 2,750 & & 3,750 & $68 \%$ \\
Gross & 2,250 & & $\$ 1,125^{\wedge *}$ & \\
Net Benefit of IPDP & & & & \\
\hline
\end{tabular}

[37] The average margin retail is nearly $50 \%$ (source Government of Canada Website)

** A 500\% margin is not uncommon

$* * *$ Freight tends to run about $10 \%$

$\wedge$ Air Freight: DHL, UPS, or Fedex

$\wedge \wedge$ Hypothetical Duty \& Tax Rate, since handicrafts tend to enter US, Canada

\& UK Duty free

$\wedge \wedge \wedge$ Flat fee brokerage

$\wedge *$ versus traditional wholesale buying, not factoring financing costs

The potential benefits for artisans can be significant. While a few wholesale sales per year would dramatically raise incomes. The Internet portal could deliver regular weekly or monthly orders from a various DC buyers. To be successful the Internet portal must provide artisans with regular re-orders. The competitive advantage of artisan production is small batch and short production cycle (1-2 weeks). The quick response would allow products to arrive on store shelves within 3-4 weeks, which would provide retail stores a competitive advantage. This approached is similar to supply chain management used by Zara Clothing which produces small batches which

\footnotetext{
${ }^{5}$ Each cluster should offer a minimum of 500 items, and be willing to customize production to customer needs. 10 clusters will offer 5,000 items from many small producers and could provide a large percentage of the product requirements for any retail store.
} 
enables quicker response to market demand. Zara is consistently more profitable than its rivals. The benefits to Zara clothing are achieved quicker responses to consumer demand resulting in less discounting and lowering carrying costs [8]. The artisan would be able to fulfil orders in a similar manner, from various customers. If the network of a few hundred buyers was established, innovative artisans could realise more consistent and larger orders. The goal is to exploit all of the artisan's leisure time so that it becomes more valuable. This should lower the artisan discount rate and provide rational incentives for investment (labour or productivity enhancing activities) in anticipation of future business. The artisan may also decide that it is worth the effort to improve the quality and raise the asking price on response to the scarcity of leisure time.

The obvious question is 'Why no one has picked up this $\$ 1,000$ bill?' [40]. The short answer is that it is difficult to change socialised behaviour. The obstacles to successful implementation of previously discussed concept do not involve setting up of development clusters. Artisan communities exist throughout the world, creating wonderful and often low quality products. Setting up handicraft clusters has been attempted at various times with varying degrees of success by various development agencies $[4,24,36]$.

This process differs from previously projects in that objective is to create demand for the product by responding to market requirements. The process may require adaptation of products to reflect contemporary needs consumer needs and would create thousands of items that could be catalogued. The biggest hindrance is finding the markets (customers). The process requires a paradigm shift in livelihood initiatives. The process of creating demand should focus in the developed world. While it seems counter intuitive to spend money in the developed world to increase the success rate of livelihood initiatives in LDC. There are thousands of potential customers (retail stores) who have the ability and incentive to invest $\$ 1,000$ many times over. There are two identifiable challenges; marketing and coordination. Marketing to potential customers could be substantially more expensive than actually making the products. Coordination issues can be addressed with current technology and the hiring of a DM. The integration process would lower transaction costs for retailers. Artisans could become crucial in the business strategy for small retailers. Artisans would help retailers differentiate product selection versus big box retailers and would become a profitable category. The development focus should be to encourage retailers to take advantage of the price differential and not attempt to impose additional costs to the transaction in the form of 'charity rents'. The focus on the profit motive, what is significantly different about this proposal is the attempt to impose NIE theory into a B2B portal. Building new institutions is difficult. The potential profit motive is the motivational tool.

Figure 1 presents a flow chart of the order and delivery process. The Internet portal would allow DC retailers to purchase products without actually travelling to DE handicraft clusters. The process would be environmentally sustainable as well as lowering the transaction costs. The order process ensures non-personal transactions. The $\mathrm{DM}$ is an agent for the buyer and the role is to coordinate the transaction while mitigating risk by verifying product quality. (S)he has a permanent presence on the 


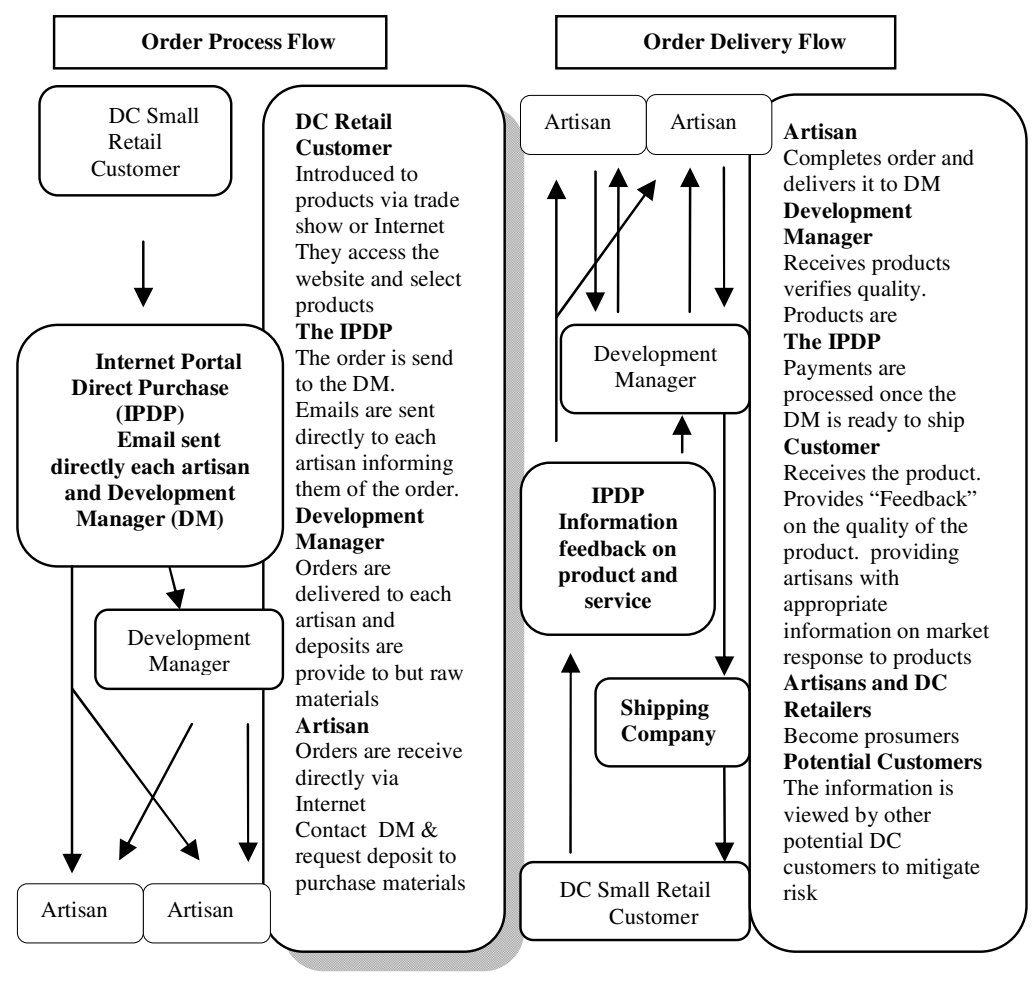

Fig. 1. Order process and delivery flow chart

community which minimises risk of artisan appropriation. The DM would work to ensure the buying process is similar to current practices in DC and is adapted to DE behaviour. The organisational structure attempts to minimise piracy and overcome the tendency to produce low quality 'Malbaratada' products. The items selected could come from various artisans allowing buyers' access to many producers. Emailing each artisan directly (if they have email) of new orders will help ensure honest DM behaviour. The artisan would be aware that there was an order and would contact the DM to arrange payment. The DM would coordinate the distribution of micro loans to facilitate the purchase of raw materials. Once production was complete the DM would arrange accept delivery of products, verify quality, pay artisan, and prepare and ship product. The DC retailer can accept product delivery with 2-3 weeks. Once product is delivered the DC retailer provides feedback on both service and products. The feedback mechanism serves multiple purposes. It provides both the artisan and DM with feedback on their service delivery. Feedback would be posted on the website. Permitting all parties to gain knowledge by 'prosuming' (producing products and information for the website while consuming information others have posted). There is a potential for learning from feedback about market demand. The DC retailers' feedback allows better decision making by current and potential customers. This process could successfully insert artisans into the global economy. 
Artisans that respond to market signals would receive appropriate information feedback and quickly learn what the customer wants and adapt production. The result will be substantially improved living standards in artisan communities. The process could involve moving up the value chain by customising production or value added processes like packaging. This should create healthy competition and a virtuous cycle of innovation. Once a critical mass as been achieved of thousands of customers the development cluster concept can be replicated in other regions within Mexico or other parts of the world.

\section{Conclusion}

This paper attempted to build upon previous research that highlighted the high failure rate of ICT4D initiatives [4]. The goal of this paper was to provide practitioners with a framework to increase the success rate of future initiatives. This research focussed on the specifics of the Mexican handicraft industry, there may be some applications to other industries or regions. Early adopters of ICT will have to take a "leap of faith" and invest monies in anticipation of future profits. All uncertainty can never be overcome, and trust never completely secure. The entrepreneur must view any investment in a new service delivery mechanism as involving forfeitable monies. ICT4D is a tool with the potential of altering the dynamics within societies and between them.

Current approaches to livelihoods aid modality tend to focus on either charity rents characterised by the fair trade movements or supply side approaches to overcoming artisan poverty. This article examined the current method and proposed a shift in emphasis to a more market based approach. The literature presented dealt with NIE explanations for development failure in the Mexican handicraft industry. A number of aspects of NIE were presented and discussed with reference to handicraft production. The concept of Agency Game theory was used to help demonstrate how basic business processes have tended to undermine both the producer and buyer in the current handicraft market. The current market involves a matrix of buyers. The overlying feature is a few wholesale and many retail/tourist (single purchase) customers. These groups of buyers undermine the successful development of the industry because their low credibility to repeat purchase encourages artisans to cheat on inputs. A new approach is needed to overcome development failure. ICT has the potential of transforming institutions and artisan incomes by connecting producers directly with global markets. Pare's [4] previous research low success rate of DE B2B initiatives. Some artisans and practitioners will always identify the difficulties; the infrastructure may never be world class, the risk too great and the profits insufficient. Internet access, as a percentage of disposable income will probably remain higher for the LDC artisans for the foreseeable future. These technical difficulties fail to fully explain why the B2B ventures have been unsustainable. The Internet is able to provide significant market information to potential buyers. The Internet has been unable to lower the transaction costs sufficiently to encourage the emergence of a B2G handicraft portal. The coordination costs or information asymmetry may still prevent successful entrepreneurial investment unless an eternal agent or DM is able to introduce elements of NIE to the industry. Success depends on overcoming institutional failure by rationally aligning the principal agent relationship. The work should be done on the margins and 
almost clandestinely to avoid institutional suppression. It requires an insertion of external agent or DM to both mitigate risk and coordinate the transaction while limiting the tendency to cheat by either party. Artisan's designs should be protected to encourage innovation. Aspects of NIE could be introduced within a non-personal transaction portal. Networks of retailers in the developed world could collectively credibly commit to repeat business. Strong property rights should promote investment in some technology that is lacking. Neo-classical theory indicates that exploiting an artisan's leisure time should encourage investments in productivity enhancing technology. While the Internet technology is readily available it is only an instrument. Success depends on building new institutions that will by-pass the current blocking agents. The focus of livelihoods projects should now include market based solutions that respond to market demand. ICT provides the possibility of connecting producers to global markets to improve livelihoods options. Research is still required on both ICT4D and contextualising NIE to local conditions.

The research presented was a theoretical explanation of low quality production. It is intended to provide development practitioners with a better understanding to some of the causes of development failure. Previous research highlighted some of the causes of B2B high failure rate. This paper provides new insights into possible solutions for the successful application of ICT4D in DE. Building a prototype will transform the concepts presented in the paper into a research project. We anticipate future research will help unlock the black box of development failure. Helping improve livelihood options for some of the most marginalise peoples.

\section{References}

1. Medina, J.F., de los Santos, E.: The Globalization of Indigenous Art: The Case of Mata Ortiz Pottery, July 22-25. American Intercontinental University Online. The University of the Incarnate Word, San Antonio (2008)

2. Boateng, R., Molla, A., Heeks, R.: E-Commerce in Developing Economies: A Review of Theoretical Frameworks and Approaches. In: Rouibah, K., Khalil, O., Ella, H.A. (eds.) Emerging Markets and E-commerce in Developing Economies, pp. 1-56. IGI Publishing, Hershey (2009)

3. Wareham, J., Zheng, J.G., Straub, D.: Critical themes in electronic commerce: a meta analysis. Journal of Information Technology 20, 1-19 (2005)

4. Pare, D.J.: Does This Site Delvier? B2B E-Commerce Services for Developing Countries. The Information Society 19, 123-134 (2003)

5. Wymer, S.A., Regan, E.A.: Factors Influencing e-commerce Adoption and Use by Small and Medium Businesses. Electronic Markets,

http: / /www. informaworld. com/smpp/title content=t713698725 (accessed on May 1, 2010)

6. Eaton, J., Samuel, K.: Technology, Geography, and Trade. Working paper, econ. dept. Boston University (2000)

7. Wood, C.M.: Marketing and E-commerce as Tools of Development in the Asia-Pacific Region: A Dual Path. International Marketing Review 21(3), 301-320 (2004)

8. Dutta, D.: http://3isite.com/articles/ ImagesFashion_Zara_Part_I.pdf (accessed in April 2010)

9. Mann, C.L.: E-Commerce in Developing Economies Policy And WTO Negotiations. In: Working Paper 00-3. Institute for International Economics, Washington, DC (2000) 
10. Jorgenson, D.W., Vu, K.: Information Technology and the World Economy. The Scandinavian Journal of Economics 107(4), 631-650 (2005); Published by Blackwell Publishing on behalf of The Scandinavian Journal of Economics, http: / /www.jstor.org/stable/3441018 (accessed on May 15, 2010)

11. Molla, A., Licker, P.S.: E-Commerce adoption in developing countries: a modeland instrumentn E-Commerce Adoption: An Commerce adoption in developing countries, http://www.sciencedirect.com/science?_ob=MImg\&_imagekey=B6VD 0-4F65K74-1-C\&_Cdi=5968\&_user=1069281\&_pii=S0378720604001314 \&_orig $=$ search\&_coverDate $=09 \% 2 \mathrm{~F} 30 \% 2 \mathrm{~F} 2005 \& \_s k=999579993 \& \mathrm{view}=$ $\mathrm{c} \& \mathrm{WChp}=\mathrm{dGLbVtz}-\mathrm{zSkzV \& md5=}$ 403d63956a10079fae55ac35ec23f0d2\&ie=/sdarticle.pdf (accessed on May 1, 2010)

12. Mokyr, J.: Innovation and its Enemies: The Economic and Political Roots of Technological Inertia. In: Olson, M., Satu, K. (eds.) A Not-So-Dismal Science: A Broader View of Economics, pp. 61-91. Oxford University Press, Oxford (2000)

13. Heeks, R., Wilson, G.: Technology. In: Allen, T., Thomas, A. (eds.) Poverty and Development: into the 21st Century, 2nd edn., pp. 23-48. Open University/Oxford University Press, Oxford (2000)

14. Batchelor, S.J., Webb, M.: E-commerce options for Third World craft producers: Final technical Report. DFID Knowledge and Research Project R7792' (2002)

15. Goldstein, A., O'Connor, D.: E-commerce for Development: Prospects and Policy Issues. Working Paper 164. OECD Development Centre, Paris (2000), http: / /www. oecd.org/dataoecd/37/61/1922730.pdf

16. Rabinovich, E., Bailey, J.P., Carter, C.R.: A Transaction-efficiency: Analysis of an Internet Retailing Supply Chain in the Music CD Industry. Decision Sciences 34(1), 131 (2003)

17. Mukhopadhyay, T., Kekre, S.: Strategic and Operational Benefits of Electronic Integration in B2B Procurement Processes. Management Science 48(10), 1301 (2002)

18. Dellarocas, C.: The Digitization of Word of Mouth: Promise and challenges of online Feedback mechanisms. Management Science 49(10), 1407-1424 (2003)

19. Gefen, D., Karahanna, E., Straub, D.W.: Consumer trust in B2C e-Commerce and the imortance of social presence: experiments in e-products and e-services. Omega 32(6), 407-424 (2004)

20. North, D.C.: The New Institutional Economics and Third World Development. In: Harris, J. (ed.) The New Institutional Economics and Third World Development, pp. 17-26. Routledge, New York (1995)

21. Leblang, D.A.: Property Rights and Economic Growth. Political Research Quarterly 49(1), 5-26 (1996)

22. Bardhan, P.: The Nature of Institutional Impediments to Economic Development. In: Olson, M., Satu, K. (eds.) A Not-So-Dismal Science: A Broader View of Economics, pp. 245-267. Oxford University Press, Oxford (2000)

23. Greif, A.: Contract Enforceability and Economic Institutions in Early Trade: The Maghribi Traders Coalition. The American Economic Review 83(3), 525-548 (1993)

24. Ba, S.: Establishing Online Trust through a Community Responsibility System. Decision Support Systems 31(3), 232-336 (2001)

25. Liebl, M., Roy, T.: Handmade in India: Preliminary Analysis of Crafts Producers and Crafts Production. Economic and Political Weekly 38(51/52), 5366-5376 (2003); Published by Economic and Political Weekly (2004),

http: / / www.jstor.org/stable/4414435 
26. Cook, S.: Price and Output Variability in a Peasant-Artisan Stone working Industry in Oaxaca, Mexico: An Analytical Essay in Economic Anthropology. American Anthropologist, New Series 72(4), 776-801 (1970), http://links.jstor.org/ sici?sici=0002-7294\%28197008\%292\%3A72\%3A4\%3C776\%

3APAOVIA $\div$ E2 . 0. CO\%3B2-V (accessed on August 21, 2007)

27. Acemoglu, D., Simon, J., James, A.R.: The Colonial Origins of Comparative Advantage: An Empirical Investigation. American Economic Review 91, 1369-1401 (2001)

28. Scrase, T.J.: Precarious Production: Globalisation and Artisan Labour in the Third World. Third World Quarterly 24(3), 449-461 (2003), http://www.jstor.org/stable/3993379

29. Aggarwal, V.K., Cedric, D.: Collaboration and Coordination in the Global Political Economy. In: Ravenhill, J. (ed.) Global Political Economy, pp. 28-49. Oxford University Press, Oxford (2005)

30. Cooter, R.D.: Law from Order: Economic Development and the Jurisprudence of Social Norms. In: Olson, M., Satu, K. (eds.) A Not-So-Dismal Science: A Broader View of Economics, pp. 245-267. Oxford University Press, Oxford (2000)

31. Knight, A.: Mexican Peonage: What Was It and Why Way It? Journal of Latin American Studies 18(1), 41-74 (1986), http://links.jstor.org/sici?sici=0022$216 \mathrm{X} \% 28198605 \% 2918 \% 3 \mathrm{~A} 1 \% 3 \mathrm{C} 41 \% 3 \mathrm{AMPWWIA} \div 3 \mathrm{E} 2.0 . \mathrm{CO} \div 3 \mathrm{~B} 2-\mathrm{T}$ (accessed on August 7, 2007)

32. Stromberg-Pellizzi, G.: Coyotes and Culture Brokers: The Production and Marketing of Txco Silverwork. In: Nash, J. (ed.) Craft Markets of the World: The Impact of Global Exchange on Middle America Artisans, pp. 85-102. State University of New York Press, New York (1993)

33. National Silver Fair Government of Guerrero. Silver fair promotion, http: / / www.guerrero.gob.mx/pics/legislacion/505/DIFNPEG.pdf (accessed in May 2010)

34. Government of Guerrero website, http://www.guerrero.gob.mx/ ?P=readart\&ArtOrder $=$ ReadArt\&Article=7331 (accessed on May 5, 2010)

35. Macaulay, S.: Non-contractual Relations in Business: A Preliminary Study. American Sociological Review 1, 55-67 (1963)

36. Tambunan, T.: Promoting Small and Medium Enterprises with a Clustering Approach: A Policy Experience from Indonesia. Journal of Small Business Management 43, 925-950 (2005)

37. Government of Canada Website, http://www.ic.gc.ca/eic/site/ retra-comde.nsf/eng/h_qn00148.html (accessed on May 15, 2010)

38. Olson, M., Satu, K. (eds.): A Not-So-Dismal Science: A Broader View of Economics. Oxford University Press, Oxford (2000)

39. North, D.C.: Institutions, Institutional Change, and Economic Performance. Cambridge University Press, Cambridge (1990)

40. Olson, M.: Big Bills left on the Sidewalk: Why Some Nations are Rich, and others Poor. In: Olson, M., Satu, K. (eds.) A Not-So-Dismal Science: A Broader View of Economics. Oxford University Press, Oxford (2000) 